\title{
PAPER
}

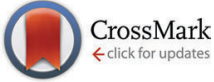

Cite this: New J. Chem., 2014 38,5761

\section{VOC sensors based on a metal oxide nanofibrous membrane/QCM system prepared by electrospinning $\dagger$}

\author{
Nesrin Horzum, ${ }^{\text {ab }}$ Didem Tascioglu, ${ }^{a}$ Cebrail Özbek, ${ }^{\text {bc }}$ Salih Okur*cd and \\ Mustafa M. Demir*ae
}

\begin{abstract}
We report a simple synthetic route to fabricate crystalline $\mathrm{ZnO}$ and $\mathrm{CeO}_{2} / \mathrm{ZnO}$ nanofibrous mats and their sensing characteristics against volatile organic compounds (VOCs) such as benzene, propanol, ethanol, and dichloromethane. Precursor fibers were fabricated by electrospinning of poly(vinyl alcohol) and metal salt(s) at $2.5 \mathrm{kV} \mathrm{cm}^{-1}$ in aqueous solution. The fibers were directly deposited on the crystal surface of a quartz crystal microbalance (QCM). The crystal, which was coated by nanostructured PVA/metal precursor(s) fibers, was subjected to calcination in air at $500{ }^{\circ} \mathrm{C}$ for $5 \mathrm{~h}$. The formation of an oxide based nanofiber mat was revealed by scanning electron microscopy and X-ray diffraction. Upon exposure of the nanofiber mats to the VOCs, the compounds adsorbed onto the surface of oxidic fibers. The physisorption of the compounds was confirmed by FTIR and QCM. Both systems showed sensitivity to the VOCs and they hold a broad promise particularly for sensing applications of volatile alcoholic compounds. The introduction of $\mathrm{CeO}_{2}$ into the $\mathrm{ZnO}$ structure reduced the sensitivity of $\mathrm{ZnO}$ most probably due to the decrement of oxygen vacancies.
\end{abstract}

Received (in Victoria, Australia) 30th May 2014, Accepted 28th August 2014

DOI: $10.1039 / c 4 n j 00884 g$

www.rsc.org/njc

\section{Introduction}

Volatile organic compounds (VOCs) are major contributors to indoor air pollution. Involuntary inhalation of VOCs leads to numerous diseases in children and elderly people particularly those having asthma, allergies, or other respiratory illness and causes special risks. Prolonged exposure to these pollutants can cause cancer, central nervous system damage, haematological problems, as well as sensitization involving the skin, eyes, and lungs. ${ }^{1-3}$ Because of the importance of indoor air quality for the health and welfare of people, the utilization of highly efficient sensors for the detection and monitoring of VOCs became a crucial attempt.

The currently available sensing approaches to detect VOCs mainly depend on the identification of output signals of optical, electrochemical, potentiometric, and quartz crystal microbalance

\footnotetext{
${ }^{a}$ Department of Chemistry, Izmir Institute of Technology, Urla, 35430, İzmir, Turkey.E-mail: mdemir@iyte.edu.tr

${ }^{b}$ Department of Engineering Sciences, İzmir Katip Çelebi University, Çiğli, 35620, İzmir, Turkey

${ }^{c}$ Department of Physics, Izmir Institute of Technology, Urla, 35430, Izmir, Turkey

${ }^{d}$ Department of Materials and Engineering, İzmir Katip Çelebi University, Çiğli, 35620, Izmir, Turkey

${ }^{e}$ Department of Materials and Engineering, Izmir Institute of Technology, Urla, 35430, Izmir, Turkey

$\dagger$ Electronic supplementary information (ESI) available: Experimental setup, EDX spectra of the fibers, and QCM responses of the fibers against 2-propanol, ethanol, and dichloromethane vapor. See DOI: 10.1039/c4nj00884g
}

(QCM) measurements. ${ }^{4-7}$ Among them, QCM sensors are stable, sensitive to mass changes even smaller than the nanogram scale, and are operated at room temperature. The operation principle of the QCM is based on resonance frequency shift upon adsorption of species on the QCM electrode. The sensing ability of the QCM toward a toxic vapor is indubitably influenced by the characteristics of coating materials that function as an adsorptive surface. To date, ceramics, metals, polymers, lipids, dendrimers, waxes, and ionic liquids have been employed as active coatings on the QCM surface. ${ }^{8-10}$ Wang and coworkers ${ }^{11}$ proposed fibrous polyethyleneimine (PEI)/polyvinyl alcohol (PVA) membranes as sensitive QCM coatings for formaldehyde sensing. The sensitivity of the fibrous membrane coated sensors was three-fold higher compared to that of flat membrane coated ones. Especially interesting is the effort made to fabricate coating that is highly sensitive to trimethylamine by the same group of authors. ${ }^{12}$ They deposited nano-nets of polyacrylic acid (PAA) membranes by electrospinning/electro-netting on a QCM electrode.

Recent attempts to enhance the sensor sensitivity and selectivity for specific analytes have focused on developing one-dimensional (1D) nanostructural coatings. ${ }^{13-15}$ Nanofibers are a broad class of 1D nanostructures, which have evoked considerable attention as sensing materials because of their excellent chemical and physical properties by virtue of gigantic aspect ratios. Probably the most versatile and practical technique for the fabrication of organic and/or inorganic nanofibers is electrospinning. ${ }^{16,17}$ This technique allows control over the 
diameter, morphology, porosity, alignment, and composition of the resulting fibers which may lead to enhanced sensing capacity compared to continuous films. ${ }^{18,19}$

The combination of semiconductor metal oxides (SMO) in nanofibers has been recognized with perfect chemical reactive surfaces that have excellent sensitivity, fast response, and recovery, which were used for vapor sensing. For example, Liu et al. have observed the toluene sensing property of the $\mathrm{NiO}-\mathrm{SnO}_{2}$ composite fiber. ${ }^{20}$ The $\mathrm{LaFeO}_{3}{ }^{21} \mathrm{ZnO}$ and $\mathrm{In}_{2} \mathrm{O}_{3}{ }^{22}$ nanofiber sensors have showed good reversibility and selectivity to ethanol. However, the optimum sensing properties of the aforementioned materials were achieved at high operating temperature, and accordingly the applied technique restricts their applicability for the detection of VOCs in the ambient environment. In our previous work, ${ }^{23}$ humidity adsorption/desorption behavior of $\mathrm{ZnO}$ nanofibrous mat was monitored by the QCM, and the sensing mechanism was proposed. A representative example to metal oxide coated QCM applications for volatile sensing is, by far, $\mathrm{TiO}_{2}$ fiber functionalized with PEI layers. However, dispersed $\mathrm{TiO}_{2}$ nanofibers were drop-casted on the electrode of the QCM. The efficient formaldehyde sensing responses of PEI-modified $\mathrm{TiO}_{2}$ fibers were attributed to both high surface area of electrospun $\mathrm{TiO}_{2}$ based fibrous mat and the interaction between formaldehyde molecules and primary amine groups of PEI. ${ }^{24}$

In the present work, QCM and electrospinning techniques were merged for the high performance sensing ability against VOCs. The fibrous metal oxide membranes were directly electrospun onto the electrode of the QCM as sensitive coatings for VOC detection and the sensing characteristics of the resulting membranes were examined. In order to investigate the effects of cerium addition and the structures of fibrous membranes on sensor sensitivity, $\mathrm{ZnO}$ as simple oxide fibers and composite $\mathrm{CeO}_{2} / \mathrm{ZnO}$ as multicompositional oxide fibers were prepared by electrospinning for the detection of frequently present VOCs in the research laboratories, including benzene, propanol, ethanol, and dichloromethane.

\section{Experimental}

\subsection{Chemicals}

Poly(vinyl alcohol) (Sigma-Aldrich, 87-90\% hydrolyzed), cerium(III) nitrate hexahydrate (Fluka, $\geq 99.0 \%$ ), zinc acetate dihydrate (SigmaAldrich, $\geq 98 \%$ ), dichloromethane (Sigma-Aldrich, 99\%), benzene (Merck, $\geq 98 \%$ ), ethanol (Merck, 96\%), and 2-propanol (Merck,
99.8\%) were all used as received. Deionized water $(18.2 \mathrm{M} \Omega \mathrm{cm})$ was used throughout the study.

\subsection{Fabrication of electrospun metal oxide nanofibers}

The metal salt, $\mathrm{Zn}\left(\mathrm{CH}_{3} \mathrm{COO}\right)_{2} \cdot 2 \mathrm{H}_{2} \mathrm{O}(2.5 \mathrm{~g}, 11.4 \mathrm{mmol})$, was added to an $18 \mathrm{wt} \%$ aqueous solution of PVA. For the fabrication of binary metal oxide fibers, $\mathrm{Zn}\left(\mathrm{CH}_{3} \mathrm{COO}\right)_{2} \cdot 2 \mathrm{H}_{2} \mathrm{O}(2.5 \mathrm{~g}, 11.4 \mathrm{mmol})$ and $\mathrm{Ce}\left(\mathrm{NO}_{3}\right)_{3} \cdot 6 \mathrm{H}_{2} \mathrm{O}(2.0 \mathrm{~g}, 4.60 \mathrm{mmol})$ were added analogously to the polymer solution. The resulting mixtures were stirred for $5 \mathrm{~h}$ in a water bath at $60{ }^{\circ} \mathrm{C}$.

The fibrous membrane coating on the QCM electrode via electrospinning is schematically depicted in Fig. 1. The viscous solutions of PVA/metal salt precursor(s) were loaded into a plastic syringe, and connected to a high voltage generator (Gamma High Voltage Research, Ormond Beach, FL, U.S.A.). As a counter electrode, a QCM crystal was removed from its electrodes and attached to the grounded aluminium foil. The supply rate was fixed at $5.5 \mathrm{~mL} \mathrm{~h}^{-1}$ using a microsyringe pump (LION WZ-50C6). The electrospinning process was performed through the QCM electrode at a $4 \mathrm{~cm}$ tip-to-collector distance for $5 \mathrm{~min}$. A voltage of $10 \mathrm{kV}$ was applied to the needle of the syringe. The electrospun fiber coated QCM was dried under vacuum at $70{ }^{\circ} \mathrm{C}$ for $8 \mathrm{~h}$ and calcined for $5 \mathrm{~h}$ at $500{ }^{\circ} \mathrm{C}$ with a heating rate of $4{ }^{\circ} \mathrm{C} \mathrm{min}{ }^{-1}$ in a chamber furnace (Protherm PLF 120/12).

\subsection{Characterization methods}

The morphological observations of the nanofibers on the QCM crystal were performed by Scanning Electron Microscopy (SEM) using a FEI Quanta 250 FEG. The average fiber diameter was calculated from SEM micrographs by using the software Fiji/ImageJ. X-Ray diffraction (XRD) patterns were acquired by using a Philips X'pert Pro diffractometer monochromatized $\mathrm{Cu}_{\mathrm{K} \alpha}$ radiation $(\lambda=1.540 \AA)$. The sizes of the crystallites were estimated by using the Scherrer equation. ${ }^{25}$ Thermogravimetric analysis (TGA) of the composite fibers was conducted using a Perkin Elmer Diamond TG/DTA. The Brunauer-Emmett-Teller (BET) surface area of the samples was measured by nitrogen adsorption using a Micromeritics Gemini V instrument. Prior to the measurement, the samples were degassed at $400{ }^{\circ} \mathrm{C}$ for $6 \mathrm{~h}$ in a vacuum to remove any adsorbed material from the fiber surface. Fourier transform infrared (FTIR) spectra were registered on a Perkin Elmer Spectrum 100 FTIR Spectrometer (Shelton, U.S.A.),

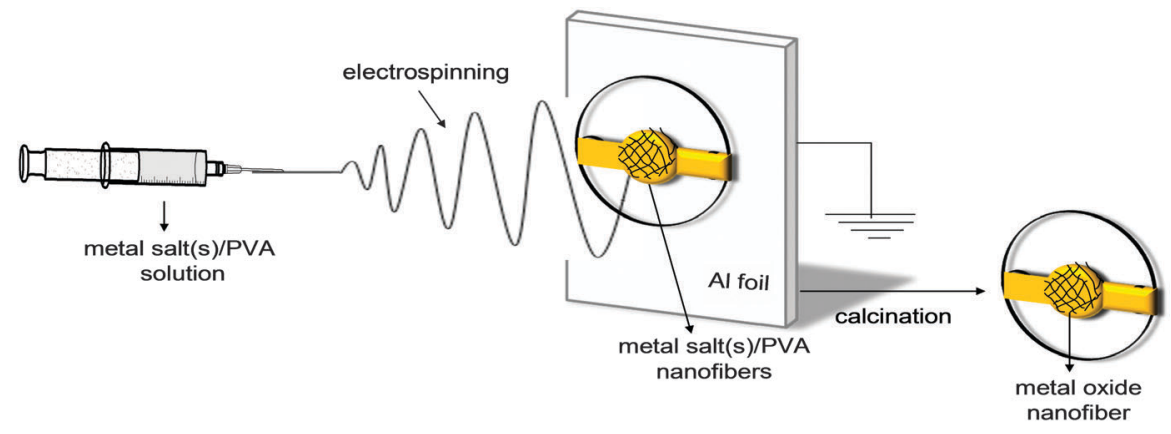

Fig. 1 Scheme of the preparation of the electrospun metal oxide fiber coated QCM. 
equipped with a Pike Miracle single reflection horizontal attenuated total reflection (ATR) accessory.

The sensing responses of metal oxide nanofibers were measured by the QCM technique. A schematic representation of the experimental setup is depicted (Fig. S1, ESI $\dagger$ ). A time-resolved QCM with the model of CHI400A Series from $\mathrm{CH}$ Instruments (Austin, USA) was used to measure the change in the resonance frequency due to the loading of volatile organic compounds after exposure of the QCM electrodes (AT-cut piezoelectric quartz crystal). The QCM electrode was inserted into the test cell $(0.1 \mathrm{~L})$ which was kept at room temperature and the $\mathrm{RH}$ of $50 \%$. The mass change $(\Delta m)$ on the surface of the quartz crystal was determined using the Sauerbrey equation: ${ }^{26}$

$$
\Delta f=-\frac{2 f_{0}^{2} \Delta m}{A \sqrt{\mu \rho}}
$$

where $\Delta f$ is the frequency change $(\mathrm{Hz})$ and $f_{0}$ is the fundamental frequency of the crystal (7.995 MHz). The density $(\rho)$ of the crystal is $2.684 \mathrm{~g} \mathrm{~cm}^{-3}$, and the shear modulus $(\mu)$ of quartz is $2.947 \times 10^{11} \mathrm{~g} \mathrm{~cm}^{-1} \mathrm{~s}^{-2}$. Around the oscillation frequency, the net change of $1 \mathrm{~Hz}$ corresponds to $1.34 \mathrm{ng}$ of gas molecules adsorbed onto the crystal surface of an area of $0.196 \mathrm{~cm}^{2}$. Gas flow into the test cell was provided by $\mathrm{N}_{2}$ calibrated mass flow meters (MKS,179A Mass-Flo ${ }^{\mathbb{R}}$ ) and the RS232 controlled gas flow control unit (MKS).

As volatile compounds, dichloromethane, benzene, ethanol, and 2-propanol were used for the adsorption process and highpurity nitrogen gas $\left(\mathrm{N}_{2}\right)$ was used for the desorption process. The change of resonance frequency of the QCM was monitored by varying the VOC ratio with the changing flow rate of VOC/ $\mathrm{N}_{2}$. The saturated vapor pressure of volatiles was determined using the Antoine equation: ${ }^{27}$

$$
\log P^{*}=A-\frac{B}{T+C}
$$

$T$ is the experimental temperature in ${ }^{\circ} \mathrm{C}$ and $A, B$, and $C$ are Antoine coefficients characteristic of the selected compounds. The concentration of volatile vapor was calculated using the following equation, assuming that the vapor behaves like an ideal gas.

$$
P^{*}=C_{\left(\mathrm{mol} \mathrm{L}^{-1}\right)} R T
$$

The concentration in the unit of ppm was determined using the relation between the molar mass $(M)$ and the density $(d)$ of the VOCs. ${ }^{28}$

$$
C_{(\mathrm{ppm})}=C_{\left(\mathrm{mol} \mathrm{L}^{-1}\right)} \times \frac{M}{d} \times 10^{6}
$$

\section{Results and discussion}

The aim of this work was to fabricate fibrous metal oxide coatings deposited directly onto the QCM electrode for the detection of VOCs such as benzene, propanol, ethanol and dichloromethane. The properties of the sensing material were presented for two metal oxide systems: electrospun $\mathrm{ZnO}$ and $\mathrm{CeO}_{2} / \mathrm{ZnO}$ composite mats.

\subsection{Fabrication and structural characterization of the metal oxide nanofibers}

Both $\mathrm{ZnO}$ and $\mathrm{CeO}_{2} / \mathrm{ZnO}$ nanofiber mats were prepared by employing similar pathways. Initially, poly(vinyl alcohol) (PVA) and a metal salt(s) $\left(\mathrm{Zn}\left(\mathrm{CH}_{3} \mathrm{COOH}\right)_{2} \cdot 2 \mathrm{H}_{2} \mathrm{O}\right.$ and/or $\left.\mathrm{Ce}\left(\mathrm{NO}_{3}\right)_{3} \cdot 6 \mathrm{H}_{2} \mathrm{O}\right)$ solution were dissolved in water. The resulting homogeneous solution was electrospun using a horizontal setup at $2.5 \mathrm{kV} \mathrm{cm}^{-1}$. The fiber mats were detached from the surface of metal substrate as free standing polymeric film. Secondly, the resulting composite fibers were converted to metal oxide fibers by controlled thermal treatment in air.

Thermal degradation of the precursor fibers of PVA/metal salt(s) is presented in Fig. 2. Three consecutive mass losses are observed at 70, 225, and $425{ }^{\circ} \mathrm{C}$ for the $\mathrm{PVA} / \mathrm{Zn}\left(\mathrm{CH}_{3} \mathrm{COOH}\right)_{2}$ fibers. They are attributed to the elimination of adsorbed water and the dehydration of zinc acetate, degradation of PVA, and decomposition of anhydrous zinc acetate to zinc oxide, respectively. ${ }^{29}$

On the other hand, the thermal decomposition of the PVA/ $\left(\mathrm{Ce}\left(\mathrm{NO}_{3}\right)_{3} / \mathrm{Zn}\left(\mathrm{CH}_{3} \mathrm{COOH}\right)_{2}\right)$ fibers showed four mass losses. In addition to the mass losses given above, the loss of coordinated water in the hydrate of cerium nitrate ${ }^{30}$ and zinc acetate is accompanied by the degradation of PVA. Further mass loss was not observed beyond $450{ }^{\circ} \mathrm{C}$ indicating the formation of fully inorganic species, $\mathrm{CeO}_{2} / \mathrm{ZnO}$. Therefore, the calcination temperature was increased and fixed at $500{ }^{\circ} \mathrm{C}$, the condition under which the removal of polymer is guaranteed. Experimentally measured metal oxide contents were 16 and $25 \%$ for $\mathrm{ZnO}$ and $\mathrm{CeO}_{2} / \mathrm{ZnO}$ systems. Theoretical contents of the remaining oxide residues can be calculated from the initially added metal salt(s) to the electrospinning solution assuming complete conversion to the corresponding oxide structure. The theoretical contents are listed in the second column of Table 1 . Surprisingly, experimentally measured metal oxide content was found to be higher than the theoretical one. This discrepancy might be due to the formation of carbonaceous species present on the surface of fibers from thermal treatment of the polymeric component.

Fig. 3 shows the XRD pattern of the metal oxide fibers obtained after calcination of PVA/Zn $\left(\mathrm{CH}_{3} \mathrm{COOH}\right)_{2} \cdot 2 \mathrm{H}_{2} \mathrm{O}$ and/or

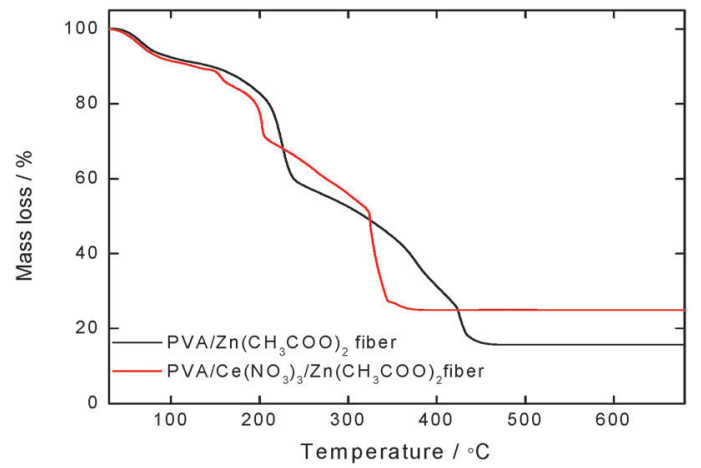

Fig. 2 TGA thermograms of PVA/Zn $\left(\mathrm{CH}_{3} \mathrm{COOH}\right)_{2}$ and PVA/Ce( $\left(\mathrm{NO}_{3}\right)_{3} /$ $\mathrm{Zn}\left(\mathrm{CH}_{3} \mathrm{COOH}\right)_{2}$ fibers. 
Table 1 Percent compositions and surface area characteristics of the metal oxide fibers

\begin{tabular}{|c|c|c|c|c|c|c|}
\hline ZnO fiber & 16 & 14 & 10 & 0.05 & 19 & 15 \\
\hline
\end{tabular}

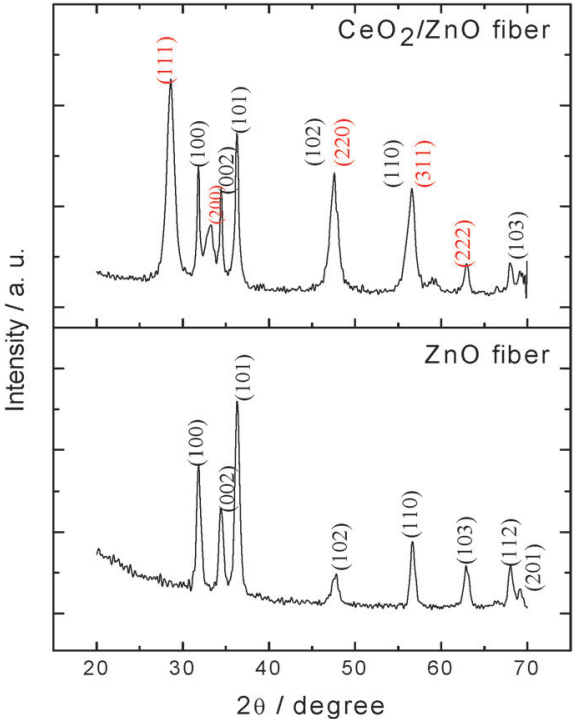

Fig. 3 XRD patterns of $\mathrm{ZnO}$ and $\mathrm{CeO}_{2} / \mathrm{ZnO}$ fibers.

$\mathrm{Ce}\left(\mathrm{NO}_{3}\right)_{3} \cdot 6 \mathrm{H}_{2} \mathrm{O}$. In the presence of cerium nitrate, the diffractogram confirms the formation of a mixed phase of the cubic fluorite structure of $\mathrm{CeO}_{2}$ (JCPDS card no. 81-0792), along with the hexagonal wurtzite structure of $\mathrm{ZnO}$ (JCPDS card no. 79-0207). The size of the crystallites estimated by the Scherrer equation ${ }^{31}$ from the (101) reflection was $15 \mathrm{~nm}$ for $\mathrm{ZnO}$ and $9 \mathrm{~nm}$ for $\mathrm{CeO}_{2} /$ ZnO fibers, respectively (Table 1). The elemental composition of the calcined fibers was also elucidated using EDX analysis which supported the XRD results (Fig. S2, ESI †). The composition of the fibers was mainly based on the corresponding metal and oxygen. BET analysis provides the surface area, pore volume and pore diameter of the calcined fibers (Table 1). The specific surface area was found to be 10 and $33 \mathrm{~m}^{2} \mathrm{~g}^{-1}$ for $\mathrm{ZnO}$ and $\mathrm{CeO}_{2} / \mathrm{ZnO}$ fibers, respectively. ZnO has a large pore size, and its surface area and pore volume are small, which indicated that the porosity in this structure is not very high. The addition of cerium salt reduces the size of $\mathrm{ZnO}$ crystallites and the pore size. As a result, the surface area and porosity of $\mathrm{CeO}_{2} / \mathrm{ZnO}$ fibers are relatively increased. Another observation is that the crystallite sizes are consistent with BET surface areas of the fibers, indicating the retardation of the crystallite growth in the two-phase system during the heat treatment. $^{32}$

Fig. 4 presents SEM micrographs and diameter distributions of $\mathrm{ZnO}$ and $\mathrm{CeO}_{2} / \mathrm{ZnO}$ fibers after calcination. The diameter of the pre-calcined fibers of PVA/zinc acetate and PVA/zinc acetate/ cerium nitrate was $315 \pm 95$ and $270 \pm 70 \mathrm{~nm}$, respectively. The addition of cerium nitrate resulted in reduction of the
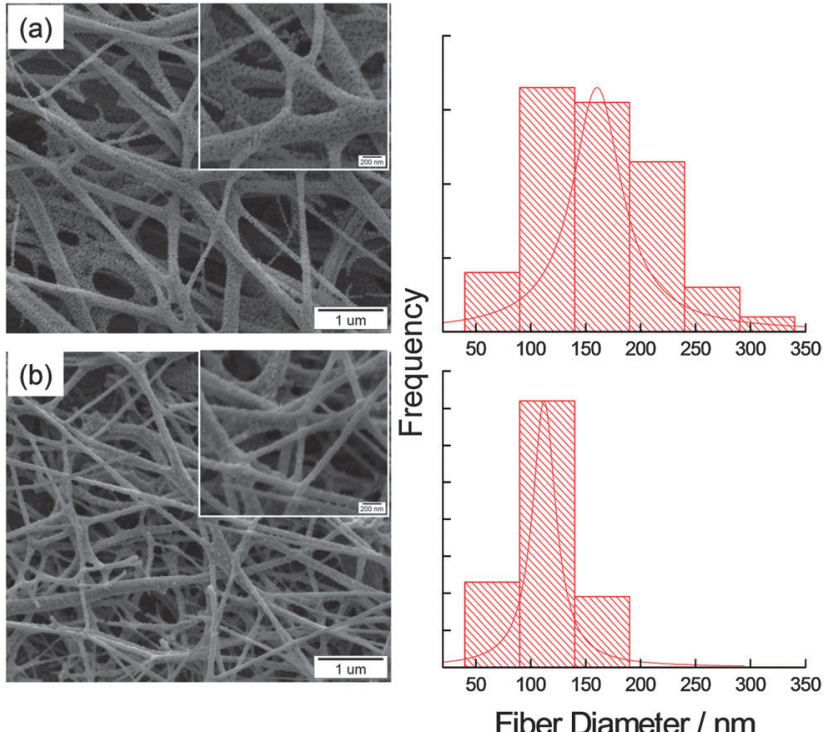

Fig. 4 SEM micrographs and diameter distributions of (a) $\mathrm{ZnO}$ and (b) $\mathrm{CeO}_{2} / \mathrm{ZnO}$ fibers.

fiber diameter in comparison to the PVA/zinc acetate fiber. This can be explained by the increase of charge density upon addition of the ceria salt. A higher elongation force leads to obtaining thinner fibers due to repulsion of the charges on the jet. ${ }^{33}$ Upon calcination at $500{ }^{\circ} \mathrm{C}$ in air, $\mathrm{ZnO}$ and $\mathrm{CeO}_{2} / \mathrm{ZnO}$ fibers were obtained while the integrity of fibers is preserved. The diameter of the fibers decreased to $160 \pm 55 \mathrm{~nm}$ for $\mathrm{ZnO}$ and $110 \pm 30 \mathrm{~nm}$ for $\mathrm{CeO}_{2} / \mathrm{ZnO}$ fibers as a result of removal of the carrier polymer and crystallization of the metal oxide phases.

\subsection{Sensing properties of metal oxide nanofibers}

Here, we examined the sensing feature of both $\mathrm{ZnO}$ and $\mathrm{CeO}_{2} / \mathrm{ZnO}$ systems. These oxide-based nanofiber mats were readily developed on the surface of the QCM electrode and used as a VOC sensor. We have also investigated the effect of $\mathrm{CeO}_{2}$ on the sensing activity of the $\mathrm{ZnO}$ nanofiber mats toward a representative VOC, benzene vapor, at room temperature. Fig. 5a shows typical adsorption/desorption characteristics of $\mathrm{ZnO}$ and $\mathrm{CeO}_{2} / \mathrm{ZnO}$ fibers. The QCM frequency counter is set to ' 0 ' $\mathrm{Hz}$ as the starting point when the $\mathrm{N}_{2}$ gas is sent through the QCM cell at $1000 \mathrm{sccm}$. In order to observe reproducibility and sensitivity of the fibrous membrane coated QCM sensors, $\mathrm{N}_{2}$ and wet $\mathrm{N}_{2}$ have been sent consecutively in 200 s periods. The change in the resonance frequency of QCM was found to be proportional to the mass of 

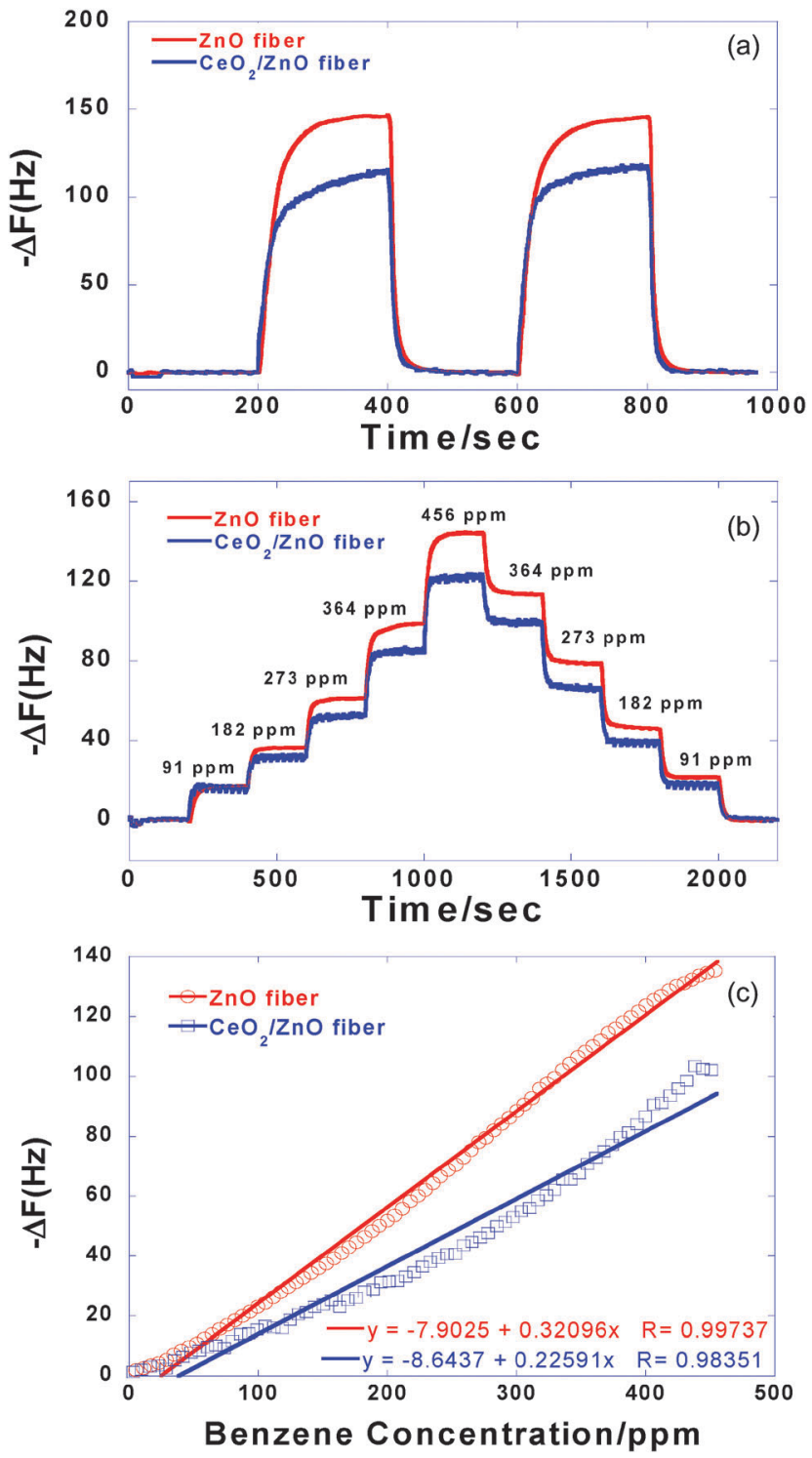

Fig. 5 (a) The two cycles of QCM responses against benzene vapor (456 ppm) as a function of time for $\mathrm{ZnO}$ and $\mathrm{CeO}_{2} / \mathrm{ZnO}$ fibers. (b) The step responses for adsorption and desorption of benzene with $\mathrm{ZnO}$ and $\mathrm{CeO}_{2} / \mathrm{ZnO}$ fiber coated QCM. (c) The linear adsorption responses of $\mathrm{ZnO}$ and $\mathrm{CeO}_{2} / \mathrm{ZnO}$ fibers as a function of benzene concentration.

the analyte adsorbed onto the QCM. This sensor system showed a stable signal with almost no hysteresis after the first two cycles.

The QCM frequency signals exhibited maxima at $116 \mathrm{~Hz}$ and $147 \mathrm{~Hz}$ for $\mathrm{CeO}_{2} / \mathrm{ZnO}$ and $\mathrm{ZnO}$ fibers, respectively. Panels $b$ and $c$ of Fig. 5 display the changes in the frequency shift of $\mathrm{CeO}_{2} / \mathrm{ZnO}$ and $\mathrm{ZnO}$ fiber coated QCM crystals measured at different concentrations of benzene vapor. In Fig. $5 \mathrm{~b}$, the level of wet $\mathrm{N}_{2}$ was increased and subsequently decreased by $200 \mathrm{sccm}$ steps with a time interval of $200 \mathrm{~s}$. The response of the sensor to benzene vapor increased gradually with increasing analyte concentrations. For the linear responses of $\mathrm{CeO}_{2} / \mathrm{ZnO}$ and $\mathrm{ZnO}$ fibers, analogously, the wet $\mathrm{N}_{2}$ level was increased by $20 \mathrm{sccm}$ for equal time intervals of $5 \mathrm{~s}$ (Fig. $5 \mathrm{c}$ ). The response of the sensor to benzene vapor increased gradually with increasing analyte concentration. The frequency shift of the QCM sensor depends on the analyte concentration and it exhibits an adequate linear correlation with benzene concentrations. The regression coefficients were 0.984 and 0.997 for $\mathrm{CeO}_{2} / \mathrm{ZnO}$ and $\mathrm{ZnO}$ fibers, respectively. Note that the data are not completely linear, especially during the start and end positions. This result may be associated with the sensitivity and saturability. At the beginning, the sensitivity is lower. At the end, there is a saturation effect for both sensing materials.

The Langmuir adsorption isotherm model has been frequently used $^{23,34-37}$ for various gases such as humidity on organic or inorganic films to describe adsorption kinetics. According to this model, the rate of surface reaction to form a monolayer on the surface is given using the following equations:

$$
\frac{\mathrm{d} \theta}{\mathrm{d} t}=k_{\mathrm{a}}(1-\theta) C-k_{\mathrm{d}} \theta
$$

$\theta$ is a unitless quantity, which expresses the fraction of surface coverage, $C$ is the gas concentration in the air, and $k_{\mathrm{a}}$ and $k_{\mathrm{d}}$ are the adsorption and desorption constants, respectively. Integration of eqn (5) leads to

$$
\theta(t)=K^{\prime}\left(1-\mathrm{e}^{-k_{\text {ads }} t}\right)
$$

where $k_{\text {ads }}$ is the inverse of the relaxation time and $K^{\prime}$ is the association constant defined as the following

$$
K^{\prime}=\frac{k_{\mathrm{a}} C}{k_{\mathrm{a}} C+k_{\mathrm{d}}} \text { and } k_{\mathrm{ads}}=k_{\mathrm{a}} C+k_{\mathrm{d}}
$$

The QCM has been used to measure the fractional coverage as a function of time during the adsorption of VOC molecules by $\mathrm{ZnO}$ or $\mathrm{CeO}_{2} / \mathrm{ZnO}$ fibers, while the increase in the frequency shift reflects the molecular mass uptake or loss. Thus, the difference between the oscillation frequency shift $(\Delta F)$ of coated and uncoated QCM is directly proportional to the adsorbed mass of VOC molecules. The relationship between the surface adsorption kinetics and frequency shift $(\Delta F)$ of QCM can be expressed as the following:

$$
\Delta F(t)=\Delta F_{\max } K^{\prime}\left(1-\mathrm{e}^{-k_{\mathrm{ads}} t}\right)
$$

Using the Sauerbrey relation, $(\Delta m=-(1.34 \mathrm{ng} / \mathrm{Hz}) \Delta F)$, the time dependent variation of mass of the adsorbed VOC molecules on the $\mathrm{ZnO}$ or $\mathrm{CeO}_{2} / \mathrm{ZnO}$ fibers surface, $\Delta m_{t}$, can be defined as the following:

$$
\begin{gathered}
\Delta m_{t}=\Delta m_{\infty}\left(1-\mathrm{e}^{-t / \tau}\right) \\
\tau^{-1}=k_{\mathrm{a}} \times C[\text { VOC molecules }]+k_{\mathrm{d}}
\end{gathered}
$$

$\Delta m_{\infty}$ is the maximum amount of adsorbed VOC molecules on the surface for $t \rightarrow \infty$ and $\tau$ is the relaxation time. Fig. 6 shows the least squares fit (solid line) using the Langmuir adsorption isotherm model given in eqn (9) for the adsorption parts of the data for $456 \mathrm{ppm}$ benzene concentration. The values of Langmuir constants were obtained from the least squares fit to the eqn (9) and are given in Table 2. The response and recovery times of $\mathrm{CeO}_{2} / \mathrm{ZnO}$ fibers were found to be $62 \mathrm{~s}$ and $18 \mathrm{~s}$, and they were $55 \mathrm{~s}$ and $20 \mathrm{~s}$ for $\mathrm{ZnO}$ fibers, respectively. A faster response time of $\mathrm{ZnO}$ fibers can be attributed to the surface characteristics 


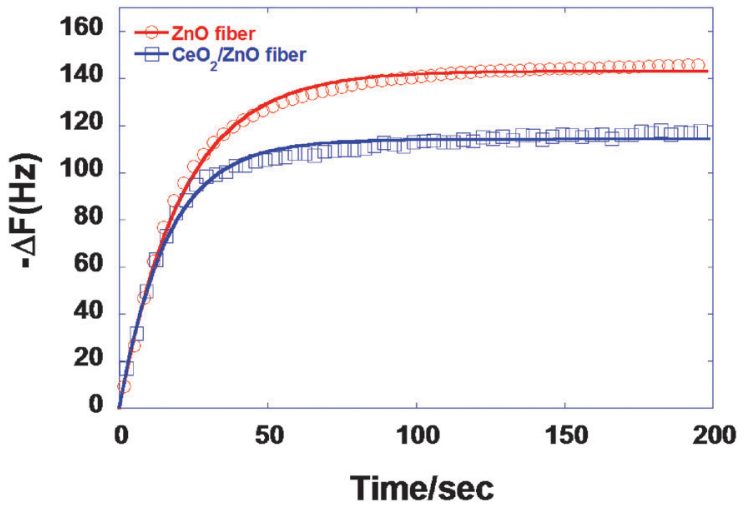

Fig. 6 Least squares fit (solid lines) using the Langmuir adsorption isotherm model for $\mathrm{ZnO}$ and $\mathrm{CeO}_{2} / \mathrm{ZnO}$ fibers against 456 ppm benzene concentration.

Table 2 The values obtained using the Langmuir adsorption isotherm model for $456 \mathrm{ppm}$ benzene concentration

\begin{tabular}{lll}
\hline & ZnO fiber & $\mathrm{CeO}_{2} /$ ZnO fiber \\
\hline$\Delta m_{\infty}(\mathrm{ng})$ & 153 & 115 \\
$\tau(\mathrm{s})$ & 23 & 16 \\
$k_{\mathrm{a}}\left(\mathrm{M}^{-1} \mathrm{~s}^{-1}\right)$ & 93 & 81 \\
$k_{\mathrm{d}}\left(\mathrm{s}^{-1}\right)$ & 0.00127 & 0.00111 \\
Response time (s) & 55 & 62 \\
Recovery time (s) & 20 & 18 \\
Chisq & 4299 & 17170 \\
$R$ & 0.999 & 0.992
\end{tabular}

corresponding to higher available active sites for sensing the target analyte.

The comparatively longer recovery time of the $\mathrm{ZnO}$ mat can be a consequence of the higher amount of benzene molecules adsorbed to its available active surface sites. Although the flux of gas propagation through the mats is fixed, $\mathrm{ZnO}$ catches a higher amount of molecules so that its desorption from the surface accordingly takes a longer time as compared to the $\mathrm{CeO}_{2} / \mathrm{ZnO}$ system.

The possible interactions between benzene vapor and the metal oxide fiber surface were identified by FTIR spectroscopy. Fig. 7 shows FT-IR spectra of the $\mathrm{ZnO}$ and $\mathrm{CeO}_{2} / \mathrm{ZnO}$ fibers before and after benzene vapor treatment. The broad absorption at around $3460 \mathrm{~cm}^{-1}$ is attributed to the presence of surface hydroxyl groups (filled diamond $\bullet$ ). The bands in the $3400 \mathrm{~cm}^{-1}$ and $1360-1475 \mathrm{~cm}^{-1}$ are assigned to Ce-O modes ${ }^{38}$ (stars ${ }^{*}$ in Fig. $7 \mathrm{~b}$ ). The increase in the intensity of the broad band between 3000 and $3800 \mathrm{~cm}^{-1}$ originates from the vibration mode of $\mathrm{CeO}_{2}$. After benzene sorption, both spectra show newly formed absorption signals at $2920 \mathrm{~cm}^{-1}$ and $1083 \mathrm{~cm}^{-1}$, (arrows $\uparrow$ ) which may be attributed to the physisorption of benzene onto the fiber surface.

The frequency shift of the $\mathrm{CeO}_{2} / \mathrm{ZnO}$ and $\mathrm{ZnO}$ fiber coated QCM sensor upon exposure to benzene, propanol, ethanol and dichloromethane vapors was measured (see Fig. S3-S4, ESI $\dagger$ ). The metal oxide fiber coated QCM sensors showed different response curves for each of the VOCs depending on their
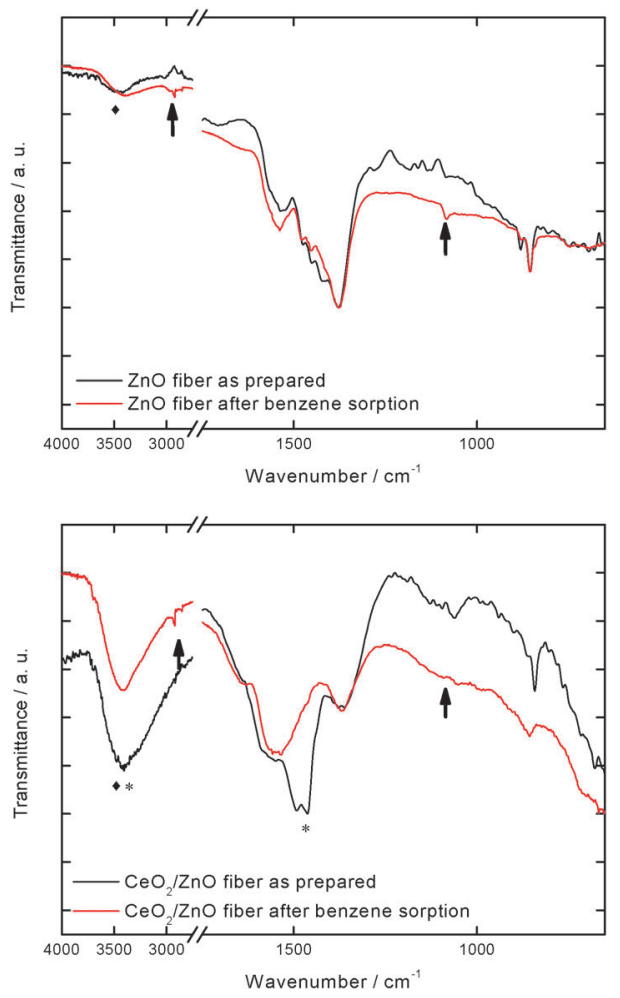

Fig. 7 FTIR spectra of (a) $\mathrm{ZnO}$ fibers and (b) $\mathrm{CeO}_{2} / \mathrm{ZnO}$ fibers, as prepared (black curve) and after benzene vapor treatment (red curve).

concentrations. The characteristics of the volatile substances are listed in Table 3. The change of frequency shift depending on the unit change of concentration is defined as sensitivity of the sensor. ${ }^{39}$ To make a more accurate comparison, the sensitivity of the $\mathrm{CeO}_{2} / \mathrm{ZnO}$ and $\mathrm{ZnO}$ fiber coated sensor to benzene, propanol, ethanol and dichloromethane vapors is presented in Fig. 8. Both $\mathrm{ZnO}$ and $\mathrm{CeO}_{2} / \mathrm{ZnO}$ systems showed sensitivity to the VOCs employed; however, ZnO fibers were found to be more effective although they provide a smaller surface area compared to $\mathrm{CeO}_{2} /$ ZnO. In comparison with the $\mathrm{CeO}_{2} / \mathrm{ZnO}$ fibers, the better sensing performance of $\mathrm{ZnO}$ fibers could be attributed to the crystal structure of the oxidic systems. ZnO has a hexagonal wurzite structure with zinc ions surrounded by tetrahedra of oxygen ions. This tetrahedral coordination results in tetrahedral symmetry and accordingly spontaneous polarity along the hexagonal axis. The polar $\mathrm{Zn}-\mathrm{O}$ bonds give rise to charge contrast between zinc and oxygen planes ${ }^{40}$ where $\mathrm{Zn}$ atoms are partially positive. Thus, lone pairs on the alcoholic compounds tend to be attracted toward the positively charged metal atoms.

On the other hand, $\mathrm{CeO}_{2}$ that has a fluorite crystal structure does not have as much polarity as $\mathrm{ZnO}$ does. This is because the addition of $\mathrm{CeO}_{2}$ into the $\mathrm{ZnO}$ structure does not seem to be effective in sensing applications although it provides a larger surface area (Table 1).

The efficiency of these materials in sensing applications did not merely originate from surface area and porosity, rather, may result from the surface chemical feature of the metal oxide systems. The sensing feature of the VOCs to the nanofiber-coated 
Table 3 Properties of the volatile organic compounds

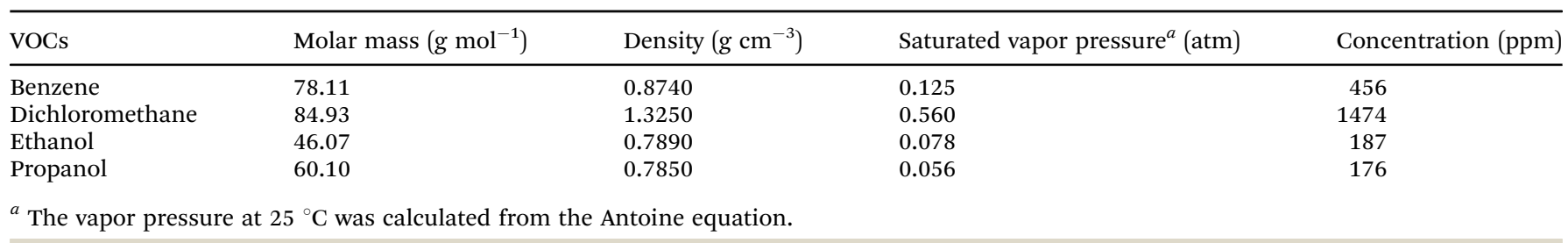

QCM is based on adsorption/desorption mechanism. This pair of processes is a surface phenomenon; therefore, surface chemistry of the sensing materials must be carefully examined. Since the metal oxide fibers were obtained by calcination of PVA and metal precursor(s), the surface of the fibers is covered by different species. For example, when the polymeric component undergoes degradation at $500{ }^{\circ} \mathrm{C}$, the formation of carbon rich organic residue on the fiber surface is highly possible. In other words, carbonaceous species may be left over from the thermal degradation of PVA. Moreover, the surface of oxides is inevitably covered with a thick layer of water molecules with different structures and mobilities. The first layer of molecules is strictly bound to the surface of metal oxide. The interaction of the molecules decreases and correspondingly their mobility increases radially outward from the metal oxide surface. ${ }^{41,42}$ Yet, the presence of both surface species (carbonaceous and surface hydroxyls) speculated here in fact was revealed by vibrational spectroscopy. The sensitivity of the oxide surfaces to benzene may be explained by the interaction of surface carbonaceous species with benzene molecules through nonpolar interactions. On the other hand, the polar oxidic surface feature may better associate with polar organic compounds for instance alcohols.

The sensing ability of the nanomaterials can also be roughly viewed from another perspective. The liability of the VOCs toward interaction with surface metal atoms can be explained based on the Lewis acid-base pairing. Higher oxygen vacant sites in the wurzite crystal structure of $\mathrm{ZnO}$ fibers refer to deficiency of negative charge; therefore, $\mathrm{ZnO}$ can be considered as Lewis acid. ${ }^{43}$ The presence of oxygen vacancy may act as trapping centers. For example, oxygen atoms due to having two lone pairs have a high electron density and the oxygen atom can donate electron pairs; thus alcohols act as Lewis base. $\mathrm{ZnO}$

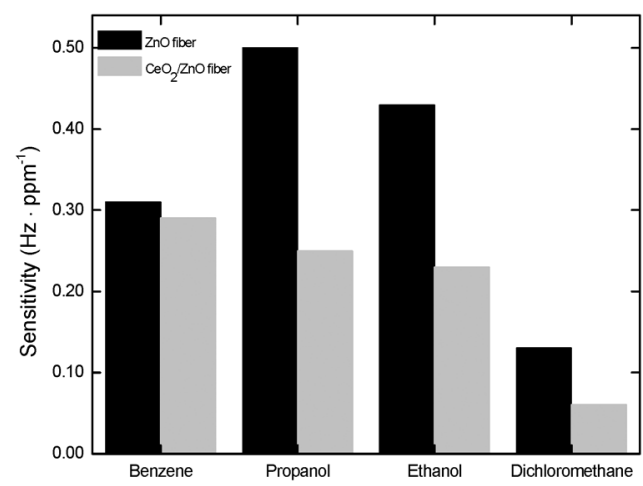

Fig. 8 Sensitivity of the $\mathrm{ZnO}$ fiber and $\mathrm{CeO}_{2} / \mathrm{ZnO}$ coated sensor to benzene, propanol, ethanol and dichloromethane vapors. shows a higher sensitivity compared to $\mathrm{CeO}_{2} / \mathrm{ZnO}$ regardless of the compounds. On the other hand, the fiber coated sensor shows low sensitivity to dichloromethane. Because of the electronegative chlorine atoms in dichloromethane, the molecule may act as a weak base making the $\mathrm{Zn}$ atom difficult to accept an electron pair from the base.

\section{Conclusions}

$\mathrm{CeO}_{2} / \mathrm{ZnO}$ and $\mathrm{ZnO}$ based nanofibers as sensitive coatings were successfully positioned on the electrode of a quartz crystal via electrospinning and subsequent calcination. Their sensing abilities based on the volatile organic compounds (benzene, propanol, ethanol, and dichloromethane) and adsorption/ desorption behaviors were examined using a quartz crystal microbalance technique. Independent of the chemistry of metal oxide, the fiber mats respond to all volatile organic compounds employed in this study. However, the $\mathrm{ZnO}$ fibrous mat exhibited better performance than $\mathrm{CeO}_{2} / \mathrm{ZnO}$ fibers most probably due to the crystal structure and the presence of higher oxygen vacancies. The sensing properties of the $\mathrm{CeO}_{2} / \mathrm{ZnO}$ and $\mathrm{ZnO}$ fiber coated quartz crystal microbalance were particularly demonstrated for the detection of benzene. The response time was found to be $55 \mathrm{~s}$ for $\mathrm{ZnO}$ fibers. On the other hand, $\mathrm{CeO}_{2} /$ $\mathrm{ZnO}$ fibers showed response within $62 \mathrm{~s}$. The sensitivity of the metal oxide surfaces to benzene can be explained by hydrophobic interaction with the surface carbonaceous species. Moreover, the ZnO fiber mat seemed to be particularly sensitive to the alcoholic type compounds based on Lewis acid-base pairing. Taking advantage of various fascinating features of the electrospun metal oxide nanofibrous mat, the coated quartz crystal microbalance sensors offer easy handling, high sensitivity, as well as good reproducibility. The preparation method of the quartz crystal microbalance coating is versatile and can also be used to fabricate several active nanofibrous materials. We envisaged that this strategy enables efficient design and development of other quartz crystal microbalance coatings toward undesirable volatile organic compounds.

\section{Acknowledgements}

The authors acknowledge the Center of Material Research at IYTE, and H. Ozgener for the FTIR analysis. The financial support from The Scientific and Technological Research Council of Turkey under project number of TBAG 109T240 is gratefully acknowledged. 


\section{Notes and references}

1 A. P. Jones, Atmos. Environ., 1999, 33, 4535-4564.

2 M. Kampa and E. Castanas, Environ. Pollut., 2008, 151, 362-367.

3 M. Hakim, Y. Y. Broza, O. Barash, N. Peled, M. Phillips, A. Amann and H. Haick, Chem. Rev., 2012, 112, 5949-5966.

4 M. A. J. Bevan, C. J. Proctor, J. Bakerrogers and N. D. Warren, Environ. Sci. Technol., 1991, 25, 788-791.

5 C. Elostua, U. Bariain, J. R. Matias, F. J. Arregui, A. Luquin and M. Laguna, Sens. Actuators, B, 2006, 115, 444-449.

6 M. Mori, H. Nishimura, Y. Itagaki, Y. Sadaoka and E. Traversa, Sens. Actuators, B, 2009, 143, 56-61.

7 P. Si, J. Mortensen, A. Kornolov, J. Denborg and P. J. Moller, Anal. Chim. Acta, 2007, 597, 223-230.

8 J. W. Grate, Chem. Rev., 2000, 100, 2627-2647.

9 A. J. Ricco, R. M. Crooks and G. C. Osbourn, Acc. Chem. Res., 1998, 31, 289-296.

10 X. M. Xu, C. Z. Li, K. M. Pei, K. Zhao, Z. B. K. Zhao and H. Y. Li, Sens. Actuators, B, 2008, 134, 258-265.

11 X. F. Wang, B. Ding, M. Sun, J. Y. Yu and G. Sun, Sens. Actuators, B, 2010, 144, 11-17.

12 X. F. Wang, B. Ding, J. Y. Yu, Y. Si, S. B. Yang and G. Sun, Nanoscale, 2011, 3, 911-915.

13 B. Ding, M. R. Wang, X. F. Wang, J. Y. Yu and G. Sun, Mater. Today, 2010, 13, 16-27.

14 D. Lee, M. Yoo, H. Seo, Y. Tak, W. G. Kim, K. Yong, S. W. Rhee and S. Jeon, Sens. Actuators, B, 2009, 135, 444-448.

15 X. H. Wang, J. Zhang and Z. Q. Zhu, Appl. Surf. Sci., 2006, 252, 2404-2411.

16 Z. M. Huang, Y. Z. Zhang, M. Kotaki and S. Ramakrishna, Compos. Sci. Technol., 2003, 63, 2223-2253.

17 W. Sigmund, J. Yuh, H. Park, V. Maneeratana, G. Pyrgiotakis, A. Daga, J. Taylor and J. C. Nino, J. Am. Ceram. Soc., 2006, 89, 395-407.

18 S. V. Fridrikh, J. H. Yu, M. P. Brenner and G. C. Rutledge, Phys. Rev. Lett., 2003, 90, 144502.

19 S. A. Theron, E. Zussman and A. L. Yarin, Polymer, 2004, 45, 2017-2030.

20 L. Liu, Y. Zhang, G. G. Wang, S. C. Li, L. Y. Wang, Y. Han, X. X. Jiang and A. G. Wei, Sens. Actuators, B, 2011, 160, 448-454.

21 H. T. Fan, X. J. Xu, X. K. Ma and T. Zhang, Nanotechnology, 2011, 22, 115502.

22 X. J. Zhang and G. J. Qiao, Appl. Surf. Sci., 2012, 258, 6643-6647.
23 N. Horzum, D. Tascioglu, S. Okur and M. M. Demir, Talanta, 2011, 85, 1105-1111.

24 X. F. Wang, F. H. Cui, J. Y. Lin, B. Ding, J. Y. Yu and S. S. Al-Deyab, Sens. Actuators, B, 2012, 171, 658-665.

25 H. P. Klug and L. E. Alexander, X-Ray Diffraction procedures: For polycrystalline and amorphous materials, John Wiley, New York, 2nd edn, 1974.

26 G. Sauerbrey, Z. Phys. A: Hadrons Nucl., 1959, 155, 206-222.

27 N. A. Lange, ed. J. A. Dean, McGraw-Hill Inc., US, 12th edn, 1979, p. 1470.

28 J. Choi, D. W. Park and S. E. Shim, Synth. Met., 2012, 162, 1513-1518.

29 X. H. Yang, C. L. Shao, H. Y. Guan, X. L. Li and H. Gong, Inorg. Chem. Commun., 2004, 7, 176-178.

30 S. J. Shih, K. B. Borisenko, L. J. Liu and C. Y. Chen, J. Nanopart. Res., 2010, 12, 1553-1559.

$31 X$-ray diffraction procedures for polycrystalline and amorphous materials, ed. H. P. Klug and L. E. Alexander, John Wiley, New York, 1974.

32 C.-S. Lee, I.-D. Kim and J.-H. Lee, Sens. Actuators, B, 2013, 181, 463-470.

33 H. Fong, I. Chun and D. H. Reneker, Polymer, 1999, 40, 4585-4592.

34 M. C. Baleanu, R. R. Nigmatullin, S. Okur and K. Ocakoglu, Commun. Nonlinear Sci. Numer. Simul., 2011, 16, 4643-4648.

35 R. Demir, S. Okur, M. Seker and M. Zor, Ind. Eng. Chem. Res., 2011, 50, 5606-5610.

36 S. Okur, C. Ceylan and E. Culcular, J. Colloid Interface Sci., 2012, 368, 470-473.

37 S. Okur, N. Uzar, N. Tekguzel, A. Erol and M. C. Arikan, Physica E, 2012, 44, 1103-1107.

38 T. Mokkelbost, I. Kaus, T. Grande and M. A. Einarsrud, Chem. Mater., 2004, 16, 5489-5494.

39 A. Islam, Z. Ismail, M. N. Ahmad, B. Saad, A. R. Othman, A. Y. M. Shakaff, A. Daud and Z. Ishak, Sens. Actuators, B, 2005, 109, 238-243.

40 Zinc oxide bulk, thin films and nanostructures: Processing, properties, and applications, ed. C. Jagadish and S. J. Pearton, Elsevier, Hong Kong, 2006.

41 M. Nagao, J. Phys. Chem., 1971, 75, 3822-3828.

42 M. M. Demir, K. Koynov, U. Akbey, C. Bubeck, I. Park, I. Lieberwirth and G. Wegner, Macromolecules, 2007, 40, 1089-1100.

43 J. Y. Hu, X. Y. Liu, Y. Q. Fan, S. H. Xie, Y. Pei, M. H. Qiao, K. N. Fan, X. X. Zhang and B. N. Zong, Chin. J. Catal., 2013, 34, 1020-1026. 